\title{
Creating a common priority vector in intuitionistic fuzzy AHP: a comparison of entropy-based and distance-based models
}

\author{
Szabolcs Duleba ${ }^{1}$ (D) $\cdot$ Ahmad Alkharabsheh ${ }^{1} \cdot$ Fatma Kutlu Gündoğdu ${ }^{2}$
}

Accepted: 7 December 2021 / Published online: 30 December 2021

(c) The Author(s) 2021

\begin{abstract}
In the case of conflicting individuals or evaluator groups, finding the common preferences of the participants is a challenging task. This statement also refers to Intuitionistic Fuzzy Analytic Hierarchy Process models, in which uncertainty of the scoring of individuals is well-handled, however, the aggregation of the modified scores is generally conducted by the conventional way of multi-criteria decision-making. This paper offers two options for this aggregation: the relatively well-known entropy-based, and the lately emerged distance-based aggregations. The manuscript can be considered as a pioneer work by analyzing the nature of distance-based aggregation under a fuzzy environment. In the proposed model, three clearly separable conflicting groups are examined, and the objective is to find their common priority vector, which can be satisfactory to all participant clusters. We have tested the model results on a real-world case study, on a public transport development decision-making problem by conducting a large-scale survey involving three different stakeholder groups of transportation. The comparison of the different approaches has shown that both entropy-based and distancebased techniques can provide a feasible solution based on their high similarity in the final ordinal and cardinal outcomes.
\end{abstract}

Keywords Intuitionistic fuzzy AHP · Group decision-making · Preference aggregation · Entropy-based aggregation · Distance-based aggregation

Szabolcs Duleba

duleba.szabolcs@mail.bme.hu

Ahmad Alkharabsheh

kharabsheh@edu.bme.hu

Fatma Kutlu Gündoğdu

kgundogdu@hho.msu.edu.tr

1 Department of Transport Technology and Economics, Budapest University of Technology and Economics, Budapest, Hungary

2 Department of Industrial Engineering, National Defense University, Turkish Air Force Academy, Yesilyurt, Istanbul, Turkey 


\section{Introduction}

Within the circle of group decision-making problems, there is a clear subset, in which the negotiation of the individuals or stakeholders is impossible or not recommended due to the risk of dominancy of one or more specific participants over the others (Feizizadeh \& Ghorbanzadeh, 2017). In this case, the decision-makers have to carefully select the appropriate method for aggregating the individual preferences, and finding the common priority vector for synthesizing the different opinions (Cabrera-Barona \& Ghorbanzadeh, 2018). Specifically, in the group Analytic Hierarchy Process, this type of problem is denoted as the aggregation of judgments/priorities in non-negotiable AHP group decision-making (Amenta et al., 2021).

Evaluating public services is a good demonstration of this kind of decision problem, since the clusters of users, service providers, and authorities are clearly separable, most likely conflicting, and organizing their negotiation is very difficult and costly (Nutt, 2006). Public transportation is not an exception from the general public services because there are at least three conflicting stakeholder groups involved in the development decision all with different objectives, interests, expertise, and motivation (Macharis \& Bernardini, 2015). It is certain that the passengers see the current public transport system differently and have specific preferences for its amelioration than the operating company or the municipality of the examined city (Duleba \& Moslem, 2018). Most likely, organizing a workshop with the participation of several citizens and representatives of the company operating the local public lines, moreover with government officers from the ministry and local municipality requires a huge effort and might not lead to an appropriate final solution due to the various characteristics of the groups (Stanley \& Stanley, 2020).

In case the negotiation is not possible or could be very likely biased, preference aggregation techniques are recommended to apply. Among them, the most well-known is the conventional Aggregation of Individual Preferences (AIP), offering two mean-based techniques to find a common priority vector: the AIP Weighted Average Mean Method (AIP WAMM) and the AIP Weighted Geometric Mean Method (AIP WGMM) (Keeney, 2009). Both methods can be also applied to stakeholder groups, provided the groups are homogenous and the conflict in preferences is rather among the stakeholders, and not among the individuals within the same group. However, these techniques handle the clusters of individuals in a very simplified way because mean-based methods do not differentiate the weights of the evaluators (or stakeholders), and equal weights are assumed. Moreover, AIP WAMM and AIP WGMM are highly sensitive to extreme evaluations which might lead to a false final ranking in the outcome of the decision-making procedure (Amenta et al., 2020).

Our paper offers two alternatives for creating the final common priorities of different stakeholder group preferences in Intuitionistic Fuzzy AHP (IFAHP) and compares these methods from the final ranking point of view. The first technique is based on the diversification value of each group and denoted as entropy-based aggregation (Xia \& Xu, 2012), in which the weights of the groups are determined by the entropy of their member preferences.

The second approach is a novel integration of vector distance minimization and the IFAHP. In this model, the weights of the groups are determined by the minimum final Euclidean distance possible by assigning the weights to different stakeholder preference vectors. Consequently, the created common preference vector will be the closest to all group vectors available by the weighting, and the total proximity will be minimal in the decision space constructed by the examined criteria. Note that this type of optimizing the group weights has just lately emerged, proposed by (Duleba \& Blahota, 2021), and the authors did not consider the possibility of its application under a fuzzy environment in their paper. Consequently, our 
research is a pioneer work for revealing the characteristics of distance-based aggregation in Intuitionistic Fuzzy AHP by using entropy-based aggregation as a benchmark.

The objective of our paper is to demonstrate these two aggregation models in detail and to compare them with each other to check the robustness of these methods. For the comparison, we present a real-world case study on a public transport development problem in the capital of Jordan, in Amman city.

Next, the literature review on fuzzy group aggregation models along with the practical applications of group IFAHP is presented, followed by the methodological descriptions of the methods and the presentation of the results of the case study. Finally, some conclusions are drawn, and recommendations are made for the future appliers of the methods.

\section{Literature review}

Analytic Hierarchy Process (AHP) is amongst the most applied multi-criteria decisionmaking methods and its popularity is still unbreakable (Chen et al., 2020). However, recently a large number of researchers prefer those models that apply fuzzy or interval numbers instead of the crisp numbers of AHP due to the insecurity of scoring in the evaluation process. Among others, basically, two types of models have emerged to tackle the possibly untrustworthy scoring problem: the Interval AHP typed models (Wu et al., 2020) and the Fuzzy AHP (Chan et al., 2019) models. In our paper, we focus on Fuzzy AHP, thus, we restrict our Literature Review to this cluster of methods. Throughout the last decades, several forms of the Fuzzy Analytic Hierarchy Process have been developed for solving complex decision problems. Apart from Fuzzy AHP (Zyoud et al., 2016), more refined models emerged within this cluster of methods, probably the most utilized are Pythagorean Fuzzy AHP (Ilbahar et al., 2018), Hesitant Fuzzy AHP (Acar et al., 2018), Interval Type-2 Fuzzy AHP (Ecer, 2020), Intuitionistic Fuzzy AHP (Liao \& Xu, 2015), and Interval-valued Intuitionistic Fuzzy AHP (Abdullah \& Najib, 2016). The evident benefit of applying any fuzzy forms of AHP over the conventional AHP models is their better capability of combining quantitative and qualitative criteria and thus, having a better comprehensive structure (Liu, Zhang, et al., 2021; Liu, Zhu, et al., 2021). Moreover, these models cope with the ambiguity and vagueness of human consciousness (Khan et al., 2021; Liu et al., 2020; Wang et al., 2008) which corresponds to most of the real-world decision-making situations.

Undoubtedly, the majority of the theoretical and practical decision problems involve multiple decision-makers and thus are considered as group problems (Li et al., 2021; Liu, Zhang, et al., 2021; Liu, Zhu, et al., 2021; Zhang et al., 2020). To solve group multiple attribute decision-making problems with intuitionistic fuzzy or interval-valued intuitionistic fuzzy information, various procedures have been developed so far (Xu \& Wang, 2012, Choudhary et al., 2021). The common purpose of these models has been the most appropriate aggregation of the individual preferences of the group members into a common, acceptable collective preference, which represents the group's global attitude to the examined problem. Up to the recent days, the basic approach towards the creation of the collective preference has been the utilization of a mean-based operator, either applying weighted averaging (Xu, 2007) or weighted geometric operator (Xu \& Yager, 2006). (Zhao et al., 2010) generalized these models by introducing the generalized intuitionistic fuzzy hybrid averaging operator and the generalized interval-valued intuitionistic fuzzy weighted averaging operator (see also Chang, 2019). 
However, (Xia \& Xu, 2012) stated that all these operators use different operational laws on membership and non-membership information and it is necessary to create a neutral model for the aggregation, which they called entropy/cross entropy-based group decision-making under an intuitionistic fuzzy environment. The same argument was expressed by (Chen \& $\mathrm{Li}, 2011$ ), which paper emphasized the objective weights of the entropy calculation. From that point, the examples of applying entropy models for intuitionistic fuzzy aggregation are numerous in the existing literature (Fu et al., 2020; Garg, 2019; Khaleie \& Fasanghari, 2012; Narayanamoorthy et al., 2019; Yao \& Wang, 2018; Yuan \& Luo, 2019).

Highlighting one of the key benefits of entropy aggregation, (Jiang et al., 2018) claimed that their intuitionistic fuzzy power aggregation operator, which is based on entropy fully takes into consideration the relationship among values and is completely driven by data, consequently, no extra information is necessary for its application.

Recently, a new approach has emerged for aggregation and for finding a common priority vector that characterizes the preferences of the whole group. These types of techniques share the same consideration. They assume that the maximum agreement of the individual respondents can be reached by determining such a common priority vector in the vector space for which the total proximity measured between the common priority vector and each individual preference vector is minimal. (He et al., 2016) developed a minimum cross-entropy model and integrated the subjective weights of all individual decision-makers into a single weight vector that is closest to all decision-makers' judgement. Among the pioneers, there is (Amenta et al., 2020), who stated that all known mean-based aggregation methods are subject to the impact of extreme preferences of some decision-makers from the examined group, so these techniques may not result in accurate global group preference. Owing to the requirement of expressing the opinion of the majority within the total participants, they developed the Common Priority Vector Procedure (CPVP), which is based on minimizing the salience and thus, the distance between the priority vectors and the common vector.

Even though we share the idea of He et al. and Amenta et al. in the fairness, less sensitivity to extreme evaluations, and objectivity characteristics of the distance-based type aggregations, in our paper, we offer an alternative for the creation of the group priority vector in Intuitionistic Fuzzy AHP. In non-negotiable Group AHP problems, the key to aggregating the individual judgements or priorities is the proper selection of weights of the participants (Amenta et al., 2021). Consequently, finding a reasonable optimization process for determining the weights of individuals, or as in our case, the weights of conflicting stakeholder groups, might lead to an improved global consensus and a satisfactory common priority preference vector.

Thus, in our proposed method, we first compute the Intuitionistic Fuzzy scores groupwisely (since the preferences of the members of each group can be considered similar, but among the groups, significant conflict can be assumed) and then optimize the weights of the groups by distance minimization and calculate the final priorities by these weights. In the following, we also demonstrate the entropy-based approach and compare it with our new distance-based aggregation procedure. In the next sections, some preliminaries are presented for Intuitionistic Fuzzy Sets followed by the detailed description of the entropy-based and distance-based aggregation techniques. Both models are applied to the same case study and also their outcomes are compared to examine the robustness of the new proposed methodology. 


\section{Intuitionistic fuzzy sets (IFSs)}

Intuitionistic fuzzy sets have extended to many multi-criteria decision-making methods. In this section, we mentioned some of the MCDM methods that incorporate with IFSs. Many researchers have extended IFSs to the analytic hierarchy process (AHP) and used it to handle more complex decision making problems (Abdullah \& Najib, 2014, 2016; Kaur, 2014; Liao \& Xu, 2015; Otay et al., 2017; Wu et al., 2013; Xu \& Liao, 2014).

In this section, some definitions of IFSs, their mathematical operations, aggregation operators, and comparison functions will be reviewed.

Definition 3.1. Let $X$ is a nonempty set. An intuitionistic fuzzy set $I$ drawn from $X$ is defined as (Atanassov, 1986, 1989, 1994):

$$
I=\left\{\left\langle x, \mu_{I}(x), \vartheta_{I}(x): x \in X\right\rangle\right\}
$$

where the functions $\mu_{I}(x), \vartheta_{I}(x): \rightarrow[0,1]$ indicate to degree of membership and nonmembership of the element $x$ from $X$ to set $I$, respectively, and for every $x \in X$, the condition $0 \leq \mu_{I}(x)+\vartheta_{I}(x) \leq 1$ has to be satisfied. Furthermore, $\pi_{I}(x)=1-\mu_{I}(x)-\vartheta_{I}(x)$ called the hesitancy degree of $x$ in $I$. For each IFS, the $\pi_{I}$ is also belong to $[0,1]$.

Definition 3.2. Suppose $\tilde{X}=\left(\mu_{x}, \vartheta_{x}\right)$ and $\tilde{Y}=\left(\mu_{y}, \vartheta_{y}\right)$ be two IFSs. Therefore, the basic mathematical operations could be defined as follows (Atanassov, 1986):

$$
\begin{gathered}
\bar{X}=\left(\vartheta_{x}, \mu_{x}\right) \\
\tilde{X}=\tilde{Y} \text { if }\left(\mu_{x}=\mu_{y} \text { and } \vartheta_{x}=\vartheta_{y}\right) \\
\tilde{X} \geq \tilde{Y} \text { if }\left(\mu_{x} \geq \mu_{y} \text { and } \vartheta_{x} \leq \vartheta_{y}\right) \\
\tilde{X} \leq \tilde{Y} \text { if }\left(\mu_{x} \leq \mu_{y} \text { and } \vartheta_{x} \geq \vartheta_{y}\right) \\
\tilde{X} \oplus \tilde{Y}=\left(\mu_{x}+\mu_{y}-\mu_{x} \mu_{y}, \vartheta_{x} \vartheta_{y}\right) \\
\tilde{X} \otimes \tilde{Y}=\left(\mu_{x} \mu_{y}, \vartheta_{x}+\vartheta_{y}-\vartheta_{x} \vartheta_{y}\right) \\
\alpha \tilde{X}=\left(1-\left(1-\mu_{x}\right)^{\alpha}, \vartheta_{x}^{\alpha}\right) \\
\tilde{X}^{\alpha}=\left(\mu_{x}^{\alpha}, 1-\left(1-\vartheta_{x}\right)^{\alpha}\right)
\end{gathered}
$$

Definition 3.3. Suppose $\tilde{X}=\left(\mu_{x}, \vartheta_{x}\right)$ is an intuitionistic fuzzy number (IFN). Intuitionistic Fuzzy Weighted Geometric Operator (IFWG) and Intuitionistic Fuzzy Weighted Arithmetic Operator (IFWA) with respect to, $w_{i}=\left(w_{1}, w_{2} \ldots \ldots ., w_{n}\right) ; w_{i} \in[0,1] ; \sum_{i=1}^{n} w_{i}=1$, is defined as follows:

$$
\begin{aligned}
& I F W G\left(\tilde{X}_{1}, \ldots \ldots, \tilde{X}_{n}\right)=\left\{\prod_{i=1}^{n} \mu_{x_{i}}^{w_{i}}, 1-\prod_{i=1}^{n}\left(1-v_{x_{i}}\right)^{w_{i}}\right\} \\
& I F W A\left(\tilde{X}_{1}, \ldots \ldots, \tilde{X}_{n}\right)=\left\{1-\prod_{i=1}^{n}\left(1-\mu_{x_{i}}\right)^{w_{i}}, \prod_{i=1}^{n} v_{x_{i}}^{w_{i}}\right\}
\end{aligned}
$$


Definition 3.4. To defuzzify intuitionistic fuzzy numbers the following score function can be used;

$$
\operatorname{Sc}=\operatorname{Score}(\tilde{X})=\frac{2 \mu_{\tilde{X}}-v_{\tilde{X}}}{2}
$$

\section{The proposed methodology}

The proposed methodology includes two phases. In the first phase, the criteria weights are determined based on the intuitionistic fuzzy AHP method regarding different decision-maker groups. In the second phase, entropy measurement combines stakeholders' orders to find the criteria' compromise ranking. A hierarchical structure that has at least three levels is developed. Level 1 shows the main goal. At Level 2, there is a finite set of $n$ criteria. Some sub-criteria may define at Level 3 associated with any criterion at Level 2 in the hierarchical structure. Intuitionistic fuzzy linguistic terms for pairwise comparisons are given in Table 1.

For the consistency analysis, Random consistency index (RI) provided by Saaty [33] is used as shown in Table 2.

The pseudo algorithm of the proposed methodology is given as follows.

Table 1 Intuitionistic fuzzy linguistic terms for pairwise comparisons

\begin{tabular}{llll}
\hline Linguistic terms & Crisp equivalents & $\mu$ (membership) & $\boldsymbol{v}$ (nonmembership) \\
\hline Absolutely low importance (AL) & 9 & 0.1 & 0.9 \\
Very low importance (VL) & 7 & 0.15 & 0.75 \\
Low importance (L) & 5 & 0.25 & 0.6 \\
Slightly low importance (SL) & 3 & 0.4 & 0.5 \\
Equality importance (EE) & 1 & 0.5 & 0.4 \\
Slightly high importance (SH) & $1 / 3$ & 0.6 & 0.25 \\
High importance (H) & $1 / 5$ & 0.6 & 0.15 \\
Very high importance (VH) & $1 / 7$ & 0.75 & 0.15 \\
Absolutely high importance (AH) & $1 / 9$ & 0.90 & 0.1 \\
\hline
\end{tabular}

Table 2 Random consistency index (RI)

\begin{tabular}{lllllllll}
\hline $\mathrm{n}$ & 2 & 3 & 4 & 5 & 6 & 7 & 8 & 9 \\
\hline $\mathrm{RI}$ & 0 & 0.58 & 0.9 & 1.12 & 1.24 & 1.32 & 1.41 & 1.45 \\
\hline
\end{tabular}


Pseudo representation of the proposed algorithm

Phase 1: Intuitionistic fuzzy analytical hierarchy process (IF-AHP)

Input: $n$ : number of main or sub-criteria $(i$ and $j=$ Alias $=1,2, \ldots n), m$ : number of groups $\left(g_{l}=g_{1}, g_{2}, \ldots, g_{m}\right), s_{g_{l}}:$ number of decision-makers in each group $\left(k=1,2, \ldots s_{g_{l}}\right), s_{g_{l}}^{k}: k^{\text {th }}$ decision - maker in group $g_{l}, p$ : number of pairwise comparison matrices,

Output: The weights of the criteria

begin

for $p=1: k \times m$ do

Step 1: Perform the consistency analysis

Step 1.a. Input linguistic intuitionistic fuzzy preferences to construct pairwise comparison matrices $\left(\tilde{R}_{i j k}^{g_{l}}=\left(\tilde{r}_{i j k}\right)_{\text {nxn }}^{g_{l}}\right)$ for each decision-maker $\left(s_{g_{l}}^{k}\right)$ in group $\left(g_{\nu}\right)$ based on Table 1 .

Step 1.b: Convert fuzzy linguistic terms into corresponding crisp numbers $\tilde{R}_{i j k}^{g_{l}} \sim R_{i j k}^{g_{l}}=\left(r_{i j k}\right)_{\mathrm{nxn}}^{g_{l}}$ based on Table 1.

Step 1.c: Aggregate the judgments of each decision-maker by using the geometric mean formula as follows:

$$
R_{i j}^{g_{l}}=\left(r_{i j}\right)_{\mathrm{nxn}}^{g_{l}}=\left[\sqrt[s_{g_{l}}^{k}]{\prod_{k=1}^{s_{g_{l}}^{k}}\left(r_{i j k}\right)_{\mathrm{nxn}}^{g_{l}}}\right] \text { for } i, j=1, \ldots, n \text { and } g_{l}=g_{1}, g_{2}, \ldots, g_{m}
$$

Reciprocal values are determined for each pairwise comparison matrices as using the following rule:

$$
\left(r_{i j}\right)_{\mathrm{nxn}}^{g_{l}}=\frac{1}{\left(r_{j i}\right)_{\mathrm{nxn}}^{g_{l}}}
$$

for each pairwise comparison matrix $R_{i j}^{g_{l}}$ compute consistency ratio (CR):

$$
\begin{aligned}
& \left(R_{i j}^{g_{L}}-\lambda_{\max } \cdot I\right) \mathrm{w}_{\mathbf{i}}=0 \\
& C I=\frac{\lambda_{\max }}{n-1} \\
& C R=\frac{C I}{R I}
\end{aligned}
$$

where $\lambda_{\max }$ is the maximum eigenvalue, $w_{\mathrm{i}}$ is the eigenvector of the matrix $R^{g_{l}}, R I$ is the random consistency index, and $I$ is the identity matrix.

end for

Step 1.d: Comment the results of classical consistency analysis

if $C R>10 \%$

return to Step 1.a

else:

go Step 2

end if

Step 2: Return to intuitionistic fuzzy numbers to find local and global weights of the criteria.

for $g_{l}=1: m$ calculate weights

Step 2.a: Convert the linguistic terms to their corresponding intuitionistic fuzzy numbers (IFNs). Aggregate the intuitionistic fuzzy numbers to construct intuitionistic fuzzy pairwise comparison matrices for each decision-maker in each group.

Step 2.b: Aggregate the IFNs by using Intuitionistic Fuzzy Weighted Geometric Operator:

$$
\begin{aligned}
& \left(\tilde{r}_{i j}\right)_{\mathrm{nxn}}^{g_{l}}=\left\langle\left[\mu_{\tilde{r}_{i j}}^{g_{l}}, v_{\tilde{r}_{i j}}^{g_{l}}\right]\right\rangle= \\
& \left(\tilde{r}_{i j}\right)_{\mathrm{nxn}}^{g_{l}}=\left\langle\left[\prod_{k=1}^{s_{g_{l}}}\left(\mu_{\tilde{r}_{i j k}}^{g_{l}}\right)^{w_{g_{l}}^{k}}\right],\left[1-\prod_{k=1}^{s_{g_{l}}}\left(1-v_{\tilde{r}_{i j k}}^{g_{l}}\right)^{w_{g_{l}}^{k}}\right]\right\rangle
\end{aligned}
$$

where the weight of decision-maker is $w_{g_{l}}^{k}=\frac{1}{s_{g_{l}}}$ and $\sum_{k=1}^{s_{g_{l}}} w_{g_{l}}^{k}=1$ for $\forall g_{l}$.

Step 2.c: Reciprocal values are determined based on the following equation:

$$
\left(\tilde{r}_{j i}\right)_{\mathrm{nxn}}^{g_{l}}=\left\langle\left[v_{\tilde{r}_{j i}}^{g_{l}}, \mu_{\tilde{r}_{j i}}^{g_{l}}\right]\right\rangle
$$


Step 2.d: To obtain local weights of each criterion in terms of each group, the weighted sum is calculated by using Intuitionistic Fuzzy Weighted Arithmetic Operator as follows:

$$
\begin{aligned}
& \left(\tilde{r}_{i}\right)^{g_{l}}=\left\langle\left[\mu_{\tilde{r}_{i}}^{g_{l}}, v_{\tilde{r}_{i}}^{g_{l}}\right]\right\rangle= \\
& \left(\tilde{r}_{i}\right)^{g_{l}}=\left\langle\left\langle\left[1-\prod_{j=1}^{n}\left(1-\mu_{\tilde{r}_{i j}}^{g_{l}}\right)^{w_{j}}\right],\left[\prod_{j=1}^{n}\left(v_{\tilde{r}_{i j}}^{g_{l}}\right)^{w_{j}}\right]\right\rangle\right.
\end{aligned}
$$

where the $w_{j}=\frac{1}{n}$ and $(j=1,2, \ldots, n), \sum_{j=1}^{n} w_{j}=1$.

Step 2.e: Defuzzify the $\left(\tilde{r}_{i}\right)^{g_{l}}$ fuzzy numbers to get crisp weights based on score function as follows

$$
r_{i}{ }^{g_{l}}=\operatorname{Score}\left(\tilde{r}_{i}{ }^{g_{l}}\right)=\frac{2 \mu_{\tilde{r}_{i}} g_{\tilde{r}_{i}}}{2}
$$

Step 2.f: Normalize the $r_{i}{ }^{g_{l}}$ values to obtain the criteria and sub-criteria weights for each group

$$
\bar{r}_{l}^{g_{l}}=\frac{r_{i}^{g_{l}}}{\sum_{i=1}^{n} r_{i}^{g_{l}}} \text { for } \forall g_{l}, g_{l}=g_{1}, g_{2}, \ldots, g_{m}
$$

Step 2.g: Compute the final weights by multiplying criteria and sub-criteria normalized weights

$$
w_{i}^{g_{l}}=\bar{r}_{l}^{g_{l}}(i \in \text { Level } 2) \times \bar{r}_{l}^{g_{l}}(i \in \text { Level } 3)
$$

where $w_{i}^{g_{l}}$ is the weight of the criterion in terms of a decision-maker group

end for

\section{end for}

Phase 2: Compute the compromise solution to find the most important criteria Input: $n$ : number of criteria $(i=1,2, \ldots n)$, $s_{g_{l}}$ : number of decision - makers in each $g_{l}$ group Output: The compromise ranking of the criteria

\section{Method 1: The entropy-based aggregation methodology}

Step 3: Compute the compromise solution

Step 3.a: Find the weighted average for each criterion as follows:

$$
w_{i}^{\text {ave. }}=\frac{\sum_{g_{l}=1}^{m} w_{i}^{g_{l}} \times s_{g_{l}}}{\sum_{g_{l}=1}^{m} s_{g_{l}}}
$$

for $g_{l}=1: m$ do:

Step 3.b: Compute the entropy measures $\left(E_{g_{l}}\right)$ for each group:

$$
\text { Entropy }=E_{g_{l}}=\sum_{i=1}^{n}\left(-\frac{1}{\ln (2)}\left(w_{i}^{g_{l}} \times \ln \left(w_{i}^{g_{l}}\right)+w_{i}^{\text {ave. }} \times \ln \left(w_{i}^{\text {ave. }}\right)\right)\right)
$$

Step 3.c: Calculate the diversification value ( $\left.\operatorname{div}_{g_{l}}\right)$ for each group:

$$
\operatorname{div}_{g_{l}}=n-E_{g_{l}}
$$

end for

group.

Step 3.d: Normalize the $\operatorname{div}_{g_{l}}$ values to find the significance level of each decision-maker

$$
\bar{w}_{g_{l}}=\frac{\operatorname{div}_{g_{l}}}{\sum_{g_{l}=1}^{m} \operatorname{div}_{g_{l}}}
$$

Step 3.e: Calculate the final compromise score of each criterion and rank them in descending order.

for $i=1: n$ do:

$$
\sum_{g_{l}=1}^{m} \bar{w}_{g_{l}} \times w_{i}^{g_{l}}
$$

end for

\section{Method 2: The distance-based aggregation methodology}

Step 3: Compute the compromise solution

Step 3.a: Solve the following mathematical problem to obtain the significance levels of each 


$$
\min \sum_{\substack{g_{l}=1 \\ g_{j} \neq 1 \\ g_{l} \neq g_{j}}}^{m} \frac{\left\|\alpha_{g_{l}} w_{i}^{g_{l}}-\alpha_{g_{j}} w_{i}^{g_{j}}\right\|}{2}
$$

s.t:

$$
\begin{gathered}
\sum_{g_{l}=1}^{m} w_{i}^{g_{l}}=1 \\
\sum_{g_{l}=1}^{m} \alpha_{g_{l}}=1 \\
\sum_{g_{j}=1}^{m} \alpha_{g_{j}}=1 \\
w_{i}^{g_{l}}>0, \alpha_{g_{l}} \geq 0, \text { and } \alpha_{g_{j}} \geq 0
\end{gathered}
$$

order.

Step 3.b: Calculate the final compromise score of each criterion and rank them in descending

for $i=1: n \mathbf{d o :}$

$$
\bar{w}_{g_{l}}=\sum_{g_{l}=1}^{m} \alpha_{g_{l}} w_{i}^{g_{l}}
$$

end for

end

Note that during the whole procedure, we merely applied the maximum eigenvector method to detect the consistency of the evaluations (since Consistency Ratio calculation cannot be used for fuzzy numbers) in the phase of Step 1. In the second phase, for the weight determination, we utilized aggregation operators (see Step 2) to obtain the weight scores of the criteria, consequently, the final compromise score calculation has not been biased by the maximum eigenvector method.

\section{The case study: public transportation in Amman City}

Amman, the capital city of Jordan, has a strategic location in the Middle East. In contrast, this location has to be exploited more to attract businesses and entrepreneurs by improving the public transportation network, enhancements needed at law and regulations, and the transportation network level. Being eager to improve the whole system will affect the economic situation of the city positively. For instance, tourism will be raised if it has a sound transportation system so the tourist will have no trouble moving around the city without getting scammed by private car companies (Gronau \& Kagermeier, 2007). On the other side, accessibility to the markets and job places will be more comfortable and smoother without any congestion. Accordingly, employers and employees will benefit from the transportation network. Complex decisions that need to be taken to have a successful system include the physical network and the legislation and laws to regulate the whole transport process (Xu et al., 2018). (Alkharabsheh \& Duleba, 2021; Alkharabsheh et al., 2019, 2021) has tackled the decision problem related to the development of public transportation in Amman city in order 
to bolster the decision- maker decisions in a rational way. Also (Moslem et al., 2020) has used an integrated approach to support the bus public system development in Amman city by using the AHP-BWM approach This paper attempts to demonstrate a new decision-making approach, which has been proposed to support the decision-makers to make the right choice related to the transportation network's improvements. Amman only has a public bus system; the study covers the public bus system and grasps its primary issue.

\subsection{Demographical overview}

This section demonstrates demographical data in Amman city capital of Jordan and shows a large-scale survey was conducted to collect a massive number of passenger preferences. To include many passengers in the decision-making to obtain public involvement in decision making.

It is not possible to include all passengers or potential passengers in decision making when it comes to improving the public transportation system in a specific area. However, an outstanding result is expected by including more passengers or potential passengers in decision-making by using a large-scale survey. The large-scale surveys with high-quality data give a factual basis for outstanding research in the sciences, specifically in the transport field. In this paper, an analytical hierarchy large-scale survey has been conducted. The large-scale survey covered the passengers and potential passengers. Collecting the data needed for this study has taken two months.

The male ratio is $53.7 \%$, and females in $46.3 \%$ of the Amman population. Therefore, all together represent $42 \%$ of the kingdom population. Table 3 represents the population percentage by age group in Amman city vs. the ratio of the participated passengers in the survey based on the age group. It is noticeable that the population percentage has been covered carefully in our large-scale survey to cover the same population percentage in our survey. However, for the first group, "0-14" hasn't been covered in this survey because this group was not available onboard or does not fulfill the minimum requirement for filling the survey. The age group of $65+$ was tough to find onboard on the public buses or have the will to fill the survey.

Owing to the criteria of public bus transport supply quality we utilized the existing body of knowledge of the field, mainly the works of (Lee, 2018), and (Lakatos \& Mándoki, 2020).

Table 3 Estimated Population of the Amman city in 2019

\begin{tabular}{lllc}
\hline Age group & $\begin{array}{l}\text { Population percentage in } \\
\text { Amman City }\end{array}$ & $\begin{array}{l}\text { Percentage of the } \\
\text { participated passenger }\end{array}$ & $\begin{array}{l}\text { Passengers covered in the } \\
\text { survey }\end{array}$ \\
\hline $0-14$ & 34.4 & 0 & 0 \\
$15-24$ & 19.8 & 31.9 & 128 \\
$25-34$ & 16.4 & 26.5 & 106 \\
$35-44$ & 12.7 & 20.5 & 82 \\
$45-54$ & 8.7 & 14 & 56 \\
$55-64$ & 4.4 & 7.1 & 28 \\
$65+$ & 3.6 & 0 & 0 \\
Total & $100 \%$ & $100 \%$ & 400 \\
\hline
\end{tabular}


Figure 1 represents the public transport supply quality elements constructed based on the authors' literature review and previous research results (Alkharabsheh et al., 2019; Gündoğdu et al., 2020).

Considering that the decision elements' supreme connections are hierarchical, there are very few dependencies among the attributes. The basic hierarchical structure made it possible to apply AHP. AHP methodology was followed in constructing the questionnaire. For the first level, the questions were asked: Compare the importance of improvement for the Transport quality and Fare criterion, and so forth for all possible pairs. Consequently, for the second and third levels, the same procedure was followed. Note that the same questionnaire was presented to all stakeholders (Passengers, Public transport Experts, and Municipal officials).

Passengers: the traveler or potential traveler uses public buses daily, weekly, or monthly basis activity. Public Transportation Experts: transportation engineers who have worked in the transportation field for a minimum of one year. Municipal officials: The municipality representatives in the transport department. The consistency analyses were performed based on Step 1. According to the consistency analysis results, the pairwise comparison matrices of five passengers and two public transportation experts were eliminated. The number of valid participants in this survey was 402 passengers, 20 Public Transportation Experts, and 5 Municipal officials.

\subsection{Results of the proposed methodology}

This section presents the results of the proposed methodology for the analyzed data. It is impossible to give all pairwise matrices for such large-scale data in this study due to page constraints. Therefore, some matrices of intermediate steps and results of the methodology will be shared to increase the proposed technique's understandability.

The linguistic terms were converted to their corresponding intuitionistic fuzzy numbers (IFNs). Aggregate the intuitionistic fuzzy numbers to construct intuitionistic fuzzy pairwise comparison matrices based on the intuitionistic fuzzy weighted geometric mean operator for each decision-maker in each group. Reciprocal values are determined based on Step 2. c. To obtain local weights of each criterion in terms of each group, the weighted sum was calculated by using the Intuitionistic Fuzzy Weighted Arithmetic Mean operator as in Step 2. $d$, and these values were defuzzified by using the equation is given in Step 2. e. Finally, the local weights of each criterion or sub-criterion were determined after the normalization steps. For the main criteria in Level 1, the aggregated judgments of the fifteen public transportation experts and the normalized versions of these assessments can be seen in Table 4.

With the same procedure, the local weights of the sub-criteria of the criterion "Fare" in terms of aggregated 15 public transportation experts' judgments were calculated as given in Table 5. For the criteria belongs to Level 2 and Level 3, the same calculations have to be performed based on Step 1 and Step 2.

We have computed the final weights by multiplying criteria and sub-criteria normalized weights by using the following formula.

$w_{i}^{g}={\overline{r_{i}}}^{g}(i \in$ Level 2$) \times{\overline{r_{i}}}^{g}(i \in$ Level 3$)$, where $w_{i}^{g}$ is the weight of the criterion in terms of a decision-maker group.

For example; for the group of public transportation experts $(g=1)$, in terms of the main criterion "Fare", the final weight of the sub-criterion "Price of one-way tickets" is calculated as follows:

$$
w_{i}^{1}={\overline{r_{4}}}^{1}(i \in \text { Level } 2) \times{\overline{r_{1}}}^{1}(i \in \text { Level } 3)=0.2902 \times 0.1043=0.0303
$$




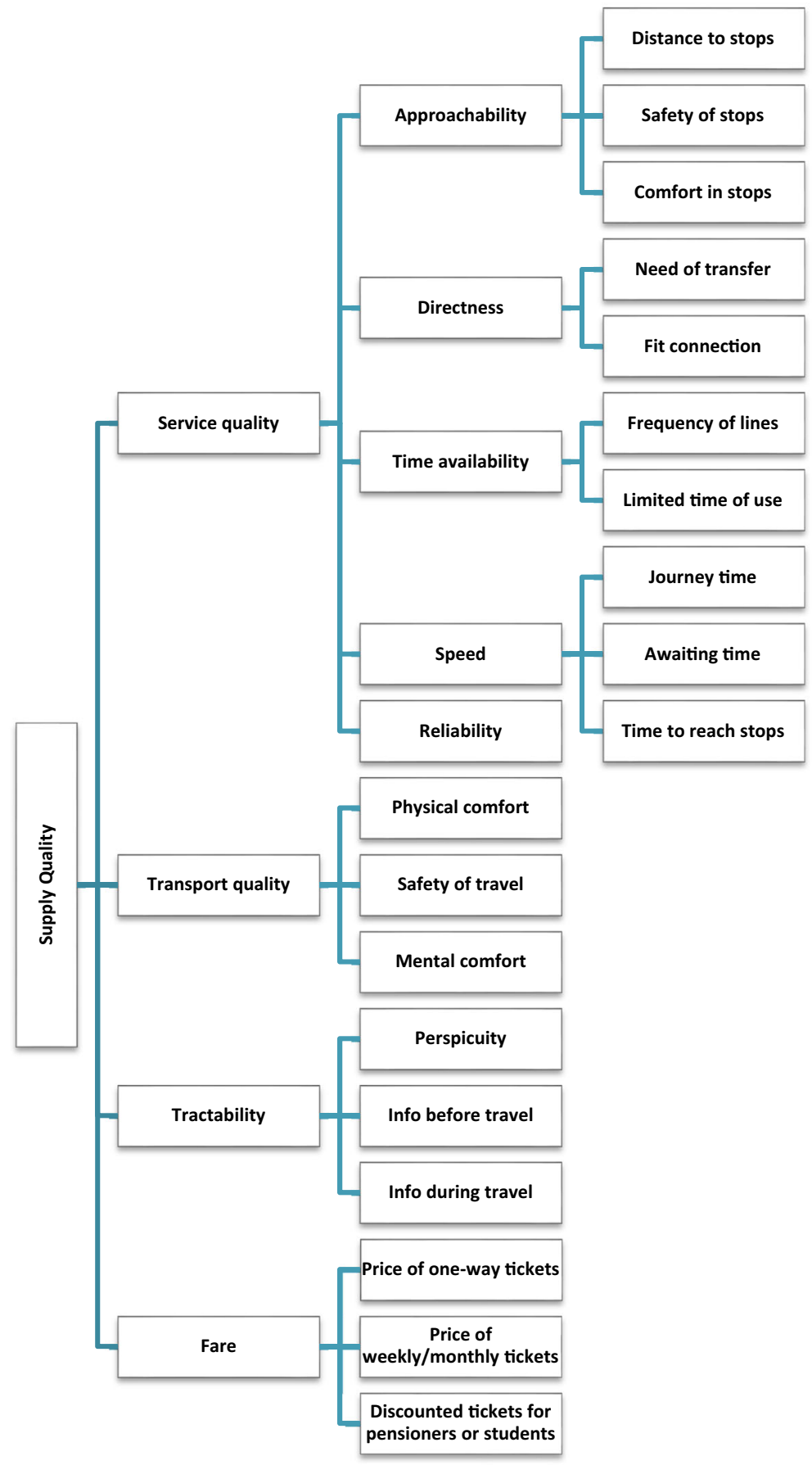

Fig. 1 The hierarchical model of public bus transport supply quality source (Alkharabsheh et al., 2019; Gündoğdu et al., 2020) 


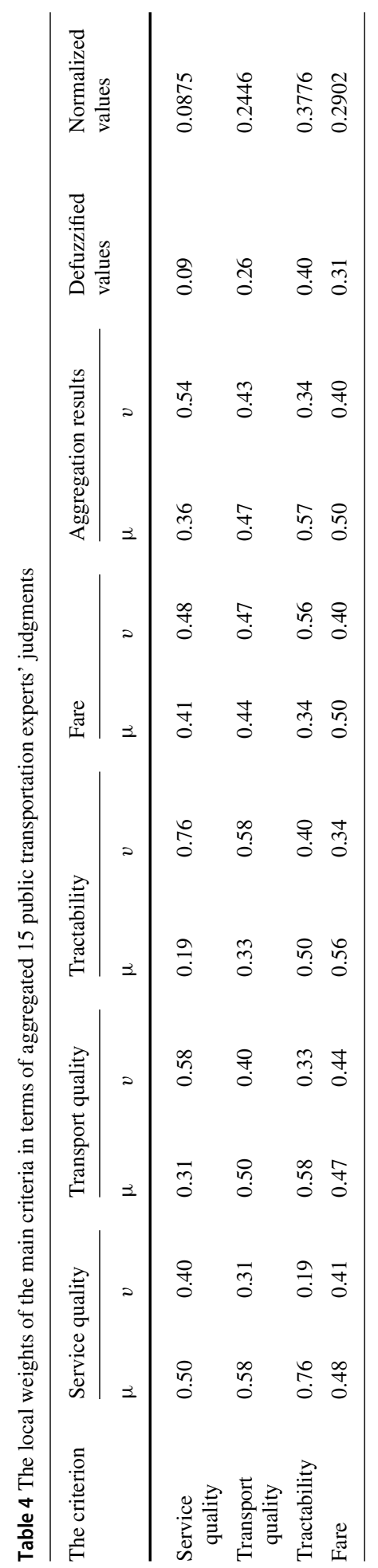




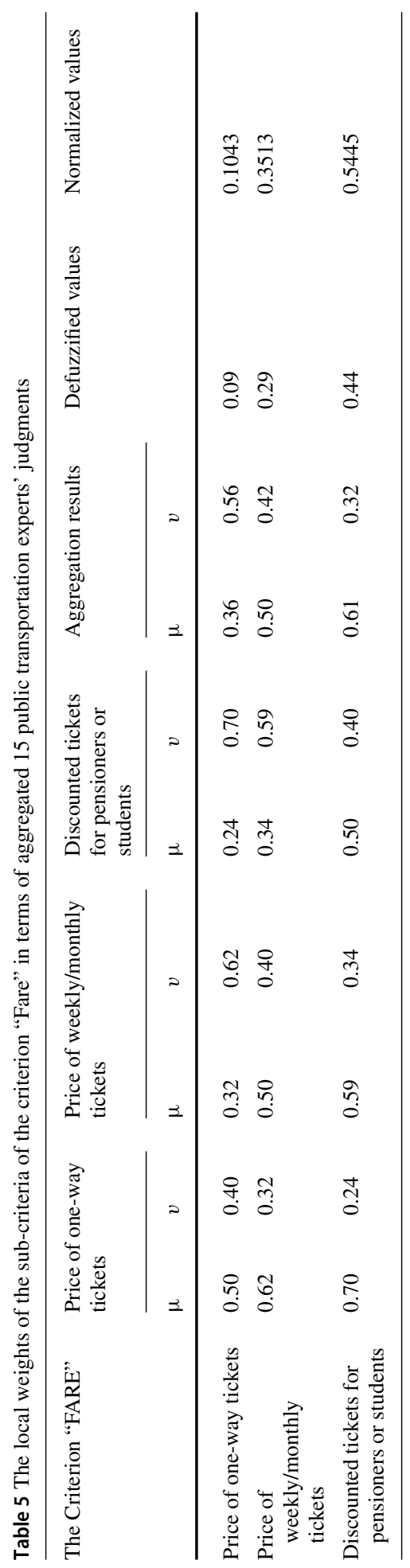


Step 1 and Step 2 are repeated for all survey participating groups that are passengers, public transport experts, and municipal officials. The final weights are shown in Table 6 . The ranking of the criteria indicates that there is no compromise solution among groups. To provide the compromise solution, Step 3 can be performed.

The weighted average score of "Service Quality" which is a main criteria is calculated based on Step 3.b. For instance: the weighted average score of the first main criteria is calculated as follows:

$$
w_{i}^{a v e .}=\frac{\sum_{g_{l}=1}^{m} w_{i}^{g_{l}} \times s_{g_{l}}}{\sum_{g_{l}=1}^{m} s_{g_{l}}}=\frac{20 \times 0.0875+402 \times 0,1362+5 \times 0.3390}{427}=0,1363
$$

To calculate the entropy measurement for the first criteria, the following formula is used.

$$
\begin{aligned}
E_{g_{l}} & =\sum_{i=1}^{n}\left(-\frac{1}{\ln (2)}\left(w_{i}^{g_{l}} \times \ln \left(w_{i}^{g_{l}}\right)+w_{i}^{a v e .} \times \ln \left(w_{i}^{a v e .}\right)\right)\right) \\
& =(-1.4427) \times(((0.0875 \times \ln (0.0875)+(0.1363 \times \ln (0.1363)) \\
& +((0.2446 \times \ln (0.2446)+(0.3100 \times \ln (0.3100))+\ldots+((0.0093 \times \ln (0.0093) \\
& +(0.0141 \times \ln (0.0141))=11.7486
\end{aligned}
$$

For the transport quality, tractability, fare criteria, and all sub-criteria we performed the same computations in terms of each group. The entropy measurement and diversification values are also shown in Table 7.

The same procedure is performed for the group of Passengers and Municipal officials to get diversification values. Table 8 shows the results belonging to the second group, which is "Passengers," while Table 9 shows the results belonging to the third group that is Municipal officials.

To find significance levels of each decision-maker group, $d i v_{g}$ values are normalized as follows:

$$
\begin{aligned}
& \bar{w}_{1}=\frac{d i v_{g_{1}}}{d i v_{g_{1}}+d i v_{g_{2}}+d i v_{g_{3}}}=\frac{16.25143}{16.25143+15.90288+14.87737}=0.345 \\
& \bar{w}_{2}=\frac{d i v_{g_{2}}}{d i v_{g_{1}}+d i v_{g_{2}}+d i v_{g_{3}}}=\frac{15.90288}{16.25143+15.90288+14.87737}=0.338 \\
& \bar{w}_{3}=\frac{d i v_{g_{3}}}{d i v_{g_{1}}+d i v_{g_{2}}+d i v_{g_{3}}}=\frac{14.87737}{16.25143+15.90288+14.87737}=0.316
\end{aligned}
$$

The weights of the public transport experts, passengers, and municipal officials are 0.345 , 0.338 , and 0.316 , respectively. Based on these weights, the compromise solution can be created based on Step 3.e as given in Table 8.

When we apply the second method called distance-based aggregation, the weights of the public transport experts, passengers, and municipal officials will be different for each level and for each branch. In the decision space, each branch represents one vector and the distance of the branches is minimized by the weight assignment. For example, on Level 1, only one branch exists, which includes Service Quality, Transport Quality, Tractability, and Fare, thus, we have one, four-dimensional vector for each group. The weights of the public transport experts, passengers, and municipal officials $0.324,0.343$, and 0.333 , respectively for Level 1 in terms of main criteria. On Level 2, we have four branches, the first includes Approachability, Directness, Time availability, Speed and Reliability criteria, the second the Physical Comfort, Mental comfort and Safety of Travel, the third Perspicuity, Info before and Info during criteria, while the fourth includes One-way tickets, Weekly/monthly tickets and Discounted tickets. 
Table 6 The final weights and ranking of each criterion in terms of decision-maker groups

\begin{tabular}{|c|c|c|c|c|c|c|c|}
\hline \multirow[t]{2}{*}{ Levels } & \multirow[t]{2}{*}{ Criteria } & \multicolumn{2}{|c|}{$\begin{array}{l}\text { Public Transportation } \\
\text { Experts }\end{array}$} & \multicolumn{2}{|c|}{ Passengers } & \multicolumn{2}{|c|}{$\begin{array}{l}\text { Municipals } \\
\text { Officials }\end{array}$} \\
\hline & & $\begin{array}{l}\text { Final } \\
\text { weights }\end{array}$ & Rank & $\begin{array}{l}\text { Final } \\
\text { weights }\end{array}$ & Rank & $\begin{array}{l}\text { Final } \\
\text { weights }\end{array}$ & Rank \\
\hline \multirow[t]{4}{*}{ Level 1} & Service Quality & 0.0875 & 4 & 0.1362 & 4 & 0.3390 & 1 \\
\hline & Transport Quality & 0.2446 & 3 & 0.3137 & 1 & 0.2805 & 2 \\
\hline & Tractability & 0.3776 & 1 & 0.2507 & 3 & 0.1493 & 4 \\
\hline & Fare & 0.2902 & 2 & 0.2994 & 2 & 0.2312 & 3 \\
\hline \multirow[t]{14}{*}{ Level 2} & Approachability & 0.0042 & 13 & 0.0105 & 14 & 0.0451 & 12 \\
\hline & Directness & 0.0229 & 12 & 0.0225 & 13 & 0.1012 & 2 \\
\hline & Time availability & 0.0340 & 9 & 0.0364 & 9 & 0.0936 & 4 \\
\hline & Speed & 0.0239 & 11 & 0.0351 & 10 & 0.0630 & 9 \\
\hline & Reliability & 0.0026 & 14 & 0.0317 & 12 & 0.0360 & 13 \\
\hline & Physical comfort & 0.0433 & 8 & 0.0484 & 8 & 0.0454 & 11 \\
\hline & Mental comfort & 0.0478 & 7 & 0.0870 & 4 & 0.0799 & 5 \\
\hline & Safety of travel & 0.1536 & 3 & 0.1783 & 2 & 0.1552 & 1 \\
\hline & Perspicuity & 0.1081 & 4 & 0.0523 & 7 & 0.0292 & 14 \\
\hline & $\begin{array}{l}\text { Information } \\
\text { before travel }\end{array}$ & 0.1930 & 1 & 0.1226 & 3 & 0.0547 & 10 \\
\hline & $\begin{array}{l}\text { Information } \\
\text { during travel }\end{array}$ & 0.0766 & 6 & 0.0758 & 6 & 0.0654 & 8 \\
\hline & $\begin{array}{l}\text { Price of One-way } \\
\text { tickets }\end{array}$ & 0.0303 & 10 & 0.0334 & 11 & 0.0664 & 6 \\
\hline & $\begin{array}{l}\text { Price of } \\
\text { weekly/monthly } \\
\text { tickets }\end{array}$ & 0.1019 & 5 & 0.0870 & 5 & 0.0991 & 3 \\
\hline & $\begin{array}{l}\text { Discounted } \\
\text { tickets }\end{array}$ & 0.1580 & 2 & 0.1790 & 1 & 0.0657 & 7 \\
\hline \multirow[t]{10}{*}{ Level 3} & Distance to stop & 0.0007 & 10 & 0.0014 & 10 & 0.0034 & 10 \\
\hline & Comfort of Stops & 0.0014 & 9 & 0.0037 & 9 & 0.0252 & 7 \\
\hline & Safety of Stops & 0.0021 & 8 & 0.0054 & 8 & 0.0166 & 8 \\
\hline & Need for transfer & 0.0070 & 6 & 0.0079 & 6 & 0.0438 & 4 \\
\hline & Fit connection & 0.0159 & 2 & 0.0147 & 4 & 0.0575 & 1 \\
\hline & $\begin{array}{l}\text { Frequency of } \\
\text { lines }\end{array}$ & 0.0139 & 3 & 0.0152 & 3 & 0.0487 & 2 \\
\hline & $\begin{array}{l}\text { Limited time of } \\
\text { use }\end{array}$ & 0.0201 & 1 & 0.0212 & 1 & 0.0449 & 3 \\
\hline & Journey time & 0.0038 & 7 & 0.0054 & 7 & 0.0097 & 9 \\
\hline & Awaiting time & 0.0108 & 4 & 0.0155 & 2 & 0.0273 & 5 \\
\hline & $\begin{array}{l}\text { Time to reach } \\
\text { stops }\end{array}$ & 0.0093 & 5 & 0.0142 & 5 & 0.0261 & 6 \\
\hline
\end{tabular}


Table 7 The diversification values of the first group

\begin{tabular}{llll}
\hline Groups & $E_{g_{l}}$ & $\operatorname{div}_{g_{l}}$ & $\bar{w}_{i}$ \\
\hline Public transportation experts & 11.74857 & 16.2514 & 0.345 \\
Passengers & 12.09712 & 15.9029 & 0.338 \\
Municipal officers & 13.12263 & 14.8773 & 0.316 \\
\hline
\end{tabular}

\begin{tabular}{|c|c|c|c|}
\hline Level & Criteria & Final weights & Level rank \\
\hline \multirow[t]{4}{*}{ Level 1} & Service quality & 0.183537 & 4 \\
\hline & Transport Quality & 0.279317 & 1 \\
\hline & Tractability & 0.262492 & 3 \\
\hline & Fare & 0.274654 & 2 \\
\hline \multirow[t]{14}{*}{ Level 2} & Approachability & 0.019261 & 14 \\
\hline & Directness & 0.047536 & 9 \\
\hline & Time availability & 0.053657 & 8 \\
\hline & Speed & 0.040073 & 12 \\
\hline & Reliability & 0.023009 & 13 \\
\hline & Physical comfort & 0.045677 & 10 \\
\hline & Mental comfort & 0.071201 & 6 \\
\hline & Safety of travel & 0.162439 & 1 \\
\hline & Perspicuity & 0.064255 & 7 \\
\hline & Info before travel & 0.125454 & 3 \\
\hline & Info during travel & 0.072784 & 5 \\
\hline & one-way tickets & 0.042762 & 11 \\
\hline & weekly/monthly tickets & 0.095979 & 4 \\
\hline & Discounted tickets & 0.135913 & 2 \\
\hline \multirow[t]{10}{*}{ Level 3} & Distance to stop & 0.001801 & 10 \\
\hline & Comfort of Stops & 0.00968 & 7 \\
\hline & Safety of Stops & 0.00778 & 8 \\
\hline & Need for transfer & 0.018916 & 4 \\
\hline & Fit connection & 0.02862 & 1 \\
\hline & Frequency of lines & 0.025333 & 3 \\
\hline & Limited time of use & 0.028325 & 2 \\
\hline & Journey time & 0.006183 & 9 \\
\hline & Awaiting time & 0.017605 & 5 \\
\hline & Time to reach stops & 0.016286 & 6 \\
\hline
\end{tabular}

Table 8 The compromise solution of the case study by entropy-based approach

On Level 3, four branches exist; the first includes Distance to stops, Comfort to stops and Safety of stops criteria, the second the Need for transfer and Fit connection attributes, the third the Frequency of lines and Limited time of use, while the fourth the Journey time, awaiting time and Time to reach stops criteria. These weights are summarized in Table 9 with the notation of the constitutional upper-level criterion. 
Table 9 The Group's weights based on hierarchy levels

\begin{tabular}{llll}
\hline Level & $\begin{array}{l}\text { Expert group's } \\
\text { weight }\end{array}$ & $\begin{array}{l}\text { Passenger group's } \\
\text { weight }\end{array}$ & $\begin{array}{l}\text { Official group's } \\
\text { weight }\end{array}$ \\
\hline Level 1 & 0.324 & 0.343 & 0.333 \\
Level 2_Service quality branch & 0.303 & 0.347 & 0.350 \\
Level 2_Transport quality & 0.322 & 0.337 & 0.341 \\
branch & & & 0.336 \\
Level 2_Tractability branch & 0.329 & 0.335 & 0.353 \\
Level 2_Fare branch & 0.328 & 0.319 & 0.313 \\
Level 3_Approachability branch & 0.347 & 0.340 & 0.344 \\
Level 3_Directness branch & 0.323 & 0.333 & 0.334 \\
Level 3_Time availability branch & 0.332 & 0.333 & 0.332 \\
Level 3_Speed branch & 0.334 & 0.333 & \\
\hline
\end{tabular}

Based on Table 9 and Step 3.b in the distance-based aggregation method, Table 10 is obtained. Table 10 indicates the compromise decision of the case study by distance optimization approach. As seen from Table 10, Fare is the most important criterion in Level 1. The criterion of "Safety of Travel" is in the first rank in Level 2. In Level 3, "Limited time of use" also takes place first.

\section{Comparative analysis}

\subsection{Ordinal comparison of the entropy- and distance-based results}

To reveal the robustness of the new proposed distance-based methodology, we have compared the gained ranking with the widely applied entropy calculation to see, how similar the rankings of the two techniques are. Obviously, the higher positive concordance values in all levels indicate the higher robustness of the distance-based common priority vector method. For the comparison, the Spearman rank correlation technique has been selected to show the similarity of the criteria ranking level-wisely.

The Spearman's Rank Correlation measures the correlation within two ranked variables. This approach measures the strength and direction of the association between two sets of knowledge when ranked by each of their quantities. The closer the worth is to \pm 1 , the stronger the connection between variables.

Spearman correlation approach used in this paper to examine the correlation between the entropy rank results and distance-based weight optimization rank results.

$$
\rho=1-\frac{6 \sum d_{i}^{2}}{n\left(n^{2}-1\right)}
$$

where $\rho=$ spearman's rank correlation coefficient, $d_{i}=$ the difference between the two ranks of each observation, and $n=$ number of observations.

Spearman correlation has been conducted for the two approaches to examine the correlation between the two methods; the correlation has been executed level wisely as each level has different criteria to be explored. 
Table 10 The compromise decision of the case study by distance optimization approach

\begin{tabular}{|c|c|c|c|}
\hline \multirow[t]{2}{*}{ Levels } & \multicolumn{3}{|l|}{ Optimized weights } \\
\hline & Criteria & Final weights & Rank \\
\hline \multirow[t]{4}{*}{ Level 1} & Service Quality & 0.188 & 4 \\
\hline & Transport Quality & 0.238 & 3 \\
\hline & Tractability & 0.259 & 2 \\
\hline & Fare & 0.274 & 1 \\
\hline \multirow[t]{14}{*}{ Level 2} & Approachability & 0.017 & 14 \\
\hline & Directness & 0.045 & 10 \\
\hline & Time availability & 0.058 & 8 \\
\hline & Speed & 0.044 & 11 \\
\hline & Reliability & 0.024 & 13 \\
\hline & Physical comfort & 0.039 & 12 \\
\hline & Mental comfort & 0.060 & 6 \\
\hline & Safety of travel & 0.139 & 1 \\
\hline & Perspicuity & 0.059 & 7 \\
\hline & Information before travel & 0.118 & 3 \\
\hline & Information during travel & 0.082 & 5 \\
\hline & Price of One-way tickets & 0.047 & 9 \\
\hline & Price of weekly/monthly tickets & 0.096 & 4 \\
\hline & Discounted tickets & 0.132 & 2 \\
\hline \multirow[t]{10}{*}{ Level 3} & Distance to stop & 0.002 & 10 \\
\hline & Comfort of Stops & 0.007 & 9 \\
\hline & Safety of Stops & 0.008 & 7 \\
\hline & Need for transfer & 0.016 & 6 \\
\hline & Fit connection & 0.029 & 2 \\
\hline & Frequency of lines & 0.026 & 3 \\
\hline & Limited time of use & 0.032 & 1 \\
\hline & Journey time & 0.007 & 8 \\
\hline & Awaiting time & 0.019 & 4 \\
\hline & Time to reach stops & 0.018 & 5 \\
\hline
\end{tabular}

As shown in Table 11, for Level 1, the elements' ordinal ranking is significantly different but still moderately similar; however, if we take a closer look, the cardinal differences are not significant because weight values of TQ, TR, and Fare are very close.

The strength of distance-based compromise becomes visible in the 2nd and 3rd levels. Due to its cardinal robustness, these two levels are strongly correlated, proved by Spearman's over $90 \%$ value. Even though the level 1 ranking was slightly different from the ordinal point of view, it was very similar to the entropy results by the cardinal weight numbers. 
Table 11 Spearman Correlation results

\begin{tabular}{lll}
\hline Levels & Approaches & $\begin{array}{l}\text { Correlation level } \\
\text { based }\end{array}$ \\
\hline Level 1 & $\begin{array}{c}\text { Entropy VS Distance-based } \\
\text { priorities }\end{array}$ & 0.400 \\
Level 2 & $\begin{array}{l}\text { Entropy VS Distance-based } \\
\text { priorities } \\
\text { Level 3 }\end{array}$ & 0.978 \\
$\quad \begin{array}{l}\text { Entropy VS Distance-based } \\
\text { priorities }\end{array}$ & 0.915 \\
\hline
\end{tabular}

\subsection{A cardinal comparison by vector compatibility calculation applying the Garuti-index}

Having analyzed the ordinal similarity of the two different approaches, to sophisticate the comparison more, we utilized the Garuti index or G-index(C. E. Garuti, 2020) to measure the vector compatibility between the preference weight vectors gained by the entropy methodology and those gained by the proposed technique, by vector distance minimization.

G-index is applicable for any two normalized (the sum of coordinates is one) vectors without further boundaries, and is especially recommended for AHP or Group AHP problems (C. Garuti, 2017). It uses a simple formula to detect if the two examined vectors are compatible and measure the extent of this compatibility.

$$
G=\frac{1}{2} \sum_{i=1}^{n} \frac{\min \left(w_{i}^{(1)}, w_{i}^{(2)}\right)}{\max \left(w_{i}^{(1)}, w_{i}^{(2)}\right)}\left(w_{i}^{(1)}+w_{i}^{(2)}\right)
$$

where $w_{i}^{(1)}$ and $w_{i}^{(2)}$ denote the $i$ th element of the first and second examined vectors. The higher the $\mathrm{G}$ index is, the more compatible the two respective vectors are. Above the value of 0.5 , the vectors are weakly compatible, the threshold for strong compatibility is 0.9 . Let us see the results of the G-index calculation for our case.

Based on Table 12, we can state that the cardinal similarity of the two different techniques is very high. Following the Garuti scaling, the consensual group preference vectors are strongly compatible in the case of all levels (the G-index of the second level is practically 90\%).

\section{Conclusion}

Common priority vector creation in non-negotiable decision problems should be based on fair weight allocation among the participating stakeholder groups. In our paper, we presented two options for this purpose and both of them could be defended from the "fairness" point of view. Entropy-based common priority applies the distribution of evaluators and scores to reach the global preference vector, while distance-based weight optimization utilizes vector distance minimization to determine the common priority vector with the minimum distance from the stakeholder group preferences. Based on the calculation results, the examined two different approaches created very similar rankings, especially for the second and third levels of the decision hierarchy in the case study, and thus, their robustness could be proven. Strictly following the principles of decision science, except for the fairness of the proposed method, the distance-based common priority vector is less sensitive to extreme evaluations of one 
Table 12 Compatibility measure of entropy and distance-based results by the Garuti index

\begin{tabular}{|c|c|c|c|}
\hline Criteria & Entropy-based approach & Distance optimization approach & G index \\
\hline Service Quality & 0.1835 & 0.1880 & 0.1814 \\
\hline Transport Quality & 0.2793 & 0.2380 & 0.2204 \\
\hline Tractability & 0.2625 & 0.2590 & 0.2573 \\
\hline Fare & 0.2747 & 0.2740 & 0.2737 \\
\hline Sum of $G$ index & 0.9327 & & \\
\hline Approachability & 0.0193 & 0.0170 & 0.0160 \\
\hline Directness & 0.0475 & 0.0450 & 0.0438 \\
\hline Time availability & 0.0537 & 0.0580 & 0.0516 \\
\hline Speed & 0.0401 & 0.0440 & 0.0383 \\
\hline Reliability & 0.0230 & 0.0240 & 0.0225 \\
\hline Physical comfort & 0.0457 & 0.0390 & 0.0361 \\
\hline Mental comfort & 0.0712 & 0.0600 & 0.0553 \\
\hline Safety of travel & 0.1624 & 0.1390 & 0.1290 \\
\hline Perspicuity & 0.0643 & 0.0590 & 0.0566 \\
\hline Info before travel & 0.1255 & 0.1180 & 0.1145 \\
\hline Info during travel & 0.0728 & 0.0820 & 0.0687 \\
\hline one-way tickets & 0.0428 & 0.0470 & 0.0408 \\
\hline weekly/monthly tickets & 0.0960 & 0.0960 & 0.0960 \\
\hline Discounted tickets & 0.1359 & 0.1320 & 0.1301 \\
\hline Sum of G index & 0.8993 & & \\
\hline Distance to stop & 0.0112 & 0.0122 & 0.0108 \\
\hline Comfort of Stops & 0.0603 & 0.0427 & 0.0364 \\
\hline Safety of Stops & 0.0485 & 0.0488 & 0.0483 \\
\hline Need for transfer & 0.1178 & 0.0976 & 0.0892 \\
\hline Fit connection & 0.1783 & 0.1768 & 0.1761 \\
\hline Frequency of lines & 0.1578 & 0.1585 & 0.1574 \\
\hline Limited time of use & 0.1764 & 0.1951 & 0.1680 \\
\hline Journey time & 0.0385 & 0.0427 & 0.0366 \\
\hline Awaiting time & 0.1097 & 0.1159 & 0.1067 \\
\hline Time to reach stops & 0.1015 & 0.1098 & 0.0976 \\
\hline Sum of G index & 0.9272 & & \\
\hline
\end{tabular}

stakeholder group or another (Amenta et al., 2020), which is an evident benefit in the case of conflicting groups.

Even though we applied real-world survey data for the demonstration of the strength of the proposed approach and conducted a comparison with a widely applied aggregation method (entropy), further investigations are necessary in the presented domain, especially, the analysis of several simulated cases to check the eligibility of the new aggregation technique. Yet, it can be considered as a limitation of the presented research. However, it can be stressed that the results so far are very promising (due to the very high similarity with the entropy calculation) and the distance minimization philosophy does not contradict the principles of 
multi-criteria decision-making considering the $n$-dimensional decision space of the $n$ number of applied criteria in the decision. To the generalization of the results, the work of (Duleba $\&$ Blahota, 2021) might also contribute, since the authors examined the nature of distance minimized compromise vector creation in group AHP in extreme preference scores and in different dimensions. Their results showed that the distance-based approach outperformed the traditional consensus creation mean-based methods and also the interval-AHP method. However, since they did not analyze the nature of distance-based aggregation under a fuzzy environment and thus, did not compare it with the entropy-based aggregation method, our research can be considered as a solid theoretical contribution to the topic.

As remark for further research, many new horizons can be opened by the presented new technique. Different distance measures can be examined, e.g., Chebyshev, Aitchison, and Manhattan distances if they can provide even more similar results with the widely applied aggregation techniques. Moreover, the methodology is possible to be applied beyond the Intuitionistic Fuzzy AHP technique and other group multi-criteria decision-making methods could also be checked for instance Fuzzy TOPSIS or group PROMETHEE models.

Acknowledgements The first author acknowledges the support of the János Bolyai Research Fellowship of the Hungarian Academy of Sciences (No.BO/8/20).

Funding Open access funding provided by Budapest University of Technology and Economics.

Open Access This article is licensed under a Creative Commons Attribution 4.0 International License, which permits use, sharing, adaptation, distribution and reproduction in any medium or format, as long as you give appropriate credit to the original author(s) and the source, provide a link to the Creative Commons licence, and indicate if changes were made. The images or other third party material in this article are included in the article's Creative Commons licence, unless indicated otherwise in a credit line to the material. If material is not included in the article's Creative Commons licence and your intended use is not permitted by statutory regulation or exceeds the permitted use, you will need to obtain permission directly from the copyright holder. To view a copy of this licence, visit http://creativecommons.org/licenses/by/4.0/.

\section{References}

Abdullah, L., \& Najib, L. (2014). A new preference scale of intuitionistic fuzzy analytic hierarchy process in multi-criteria decision making problems. Journal of Intelligent \&amp; Fuzzy Systems, 26(2), 1039-1049. https://doi.org/10.3233/IFS-130796

Abdullah, L., \& Najib, L. (2016). A new preference scale mcdm method based on interval-valued intuitionistic fuzzy sets and the analytic hierarchy process. Soft Computing, 20(2), 511-523. https://doi.org/10.1007/ s00500-014-1519-y

Acar, C., Beskese, A., \& Temur, G. T. (2018). Sustainability analysis of different hydrogen production options using hesitant fuzzy AHP. International Journal of Hydrogen Energy, 43(39), 18059-18076. https://doi. org/10.1016/j.ijhydene.2018.08.024

Alkharabsheh, A., \& Duleba, S. (2021). Public Transportation service quality evaluation during the COVID-19 pandemic in Amman City using integrated approach fuzzy AHP-Kendall model. Vehicles, 3(3), 330-340. https://doi.org/10.3390/vehicles3030020

Alkharabsheh, A., Moslem, S., \& Duleba, S. (2019). Evaluating passenger demand for development of the urban transport system by an AHP model with the real-world application of Amman. Applied Sciences, 9(22), 4759. https://doi.org/10.3390/app9224759

Alkharabsheh, A., Moslem, S., Oubahman, L., \& Duleba, S. (2021). An integrated approach of multi-criteria decision-making and grey theory for evaluating urban public transportation systems. Sustainability, 13(5), 2740.

Amenta, P., Ishizaka, A., Lucadamo, A., Marcarelli, G., \& Vyas, V. (2020). Computing a common preference vector in a complex multi-actor and multi-group decision system in analytic hierarchy process context. Annals of Operations Research. https://doi.org/10.1007/s10479-019-03258-3 
Amenta, P., Lucadamo, A., \& Marcarelli, G. (2021). On the choice of weights for aggregating judgments in non-negotiable AHP group decision making. European Journal of Operational Research, 288(1), 294-301. https://doi.org/10.1016/j.ejor.2020.05.048

Atanassov, K. T. (1986). Intuitionistic fuzzy sets. Fuzzy Sets and Systems, 20(1), 87-96. https://doi.org/10. 1016/S0165-0114(86)80034-3

Atanassov, K. T. (1989). More on intuitionistic fuzzy sets. Fuzzy Sets and Systems, 33(1), 37-45. https://doi. org/10.1016/0165-0114(89)90215-7

Atanassov, K. T. (1994). New operations defined over the intuitionistic fuzzy sets. Fuzzy Sets and Systems, 61(2), 137-142. https://doi.org/10.1016/0165-0114(94)90229-1

Cabrera-Barona, P., \& Ghorbanzadeh, O. (2018). Comparing classic and interval analytical hierarchy process methodologies for measuring area-level deprivation to analyze health inequalities. International Journal of Environmental Research and Public Health. https://doi.org/10.3390/ijerph15010140

Chan, H. K., Sun, X., \& Chung, S. H. (2019). When should fuzzy analytic hierarchy process be used instead of analytic hierarchy process? Decision Support Systems. https://doi.org/10.1016/j.dss.2019.113114

Chen, T. Y., \& Li, C. H. (2011). Objective weights with intuitionistic fuzzy entropy measures and computational experiment analysis. Applied Soft Computing Journal. https://doi.org/10.1016/j.asoc.2011.05.018

Chen, Z., Zhou, L., Yang, M., Luo, F., Lou, Z., Zhang, X., \& Wang, X. (2020). Index design and safety evaluation of pesticides application based on a fuzzy AHP model for beverage crops: Tea as a case study. Pest Management Science. https://doi.org/10.1002/ps.5539

Duleba, S., \& Blahota, I. (2021). Determining optimal group weights for consensus creation in AHP for three conflicting stakeholder groups by vector distance minimization. Journal of the Operational Research Society. https://doi.org/10.1080/01605682.2021.1918588

Duleba, S., \& Moslem, S. (2018). Sustainable Urban transport development with Stakeholder participation, an AHP-Kendall model: a case study for Mersin. Sustainability, 10(10), 3647. https://doi.org/10.3390/ su10103647

Ecer, F. (2020). Multi-criteria decision making for green supplier selection using interval type-2 fuzzy AHP: A case study of a home appliance manufacturer. Operational Research. https://doi.org/10.1007/s12351020-00552-y

Feizizadeh, B., \& Ghorbanzadeh, O. (2017). GIS-based interval pairwise comparison matrices as a novel approach for optimizing an analytical hierarchy process and multiple criteria weighting. Gi_forum, 1, 27-35.

Fu, S., Zhou, H., \& Xiao, Y.-Z. (2020). Optimum selection of energy service company based on intuitionistic fuzzy entropy and VIKOR framework. IEEE Access, 8, 186572-186584. https://doi.org/10.1109/ ACCESS.2020.3030651

Garg, H. (2019). Generalized intuitionistic fuzzy entropy-based approach for solving multi-attribute decisionmaking problems with unknown attribute weights. Proceedings of the National Academy of Sciences, India Section a: Physical Sciences, 89(1), 129-139. https://doi.org/10.1007/s40010-017-0395-0

Garuti, C. (2017). Reflections On Scales From Measurements, Not Measurements From Scales. International Journal of the Analytic Hierarchy Process. https://doi.org/10.13033/ijahp.v9i3.522

Garuti, C. E. (2020). A set theory justification of Garuti's compatibility index. Journal of Multi-Criteria Decision Analysis, 27(1-2), 50-60. https://doi.org/10.1002/mcda.1667

Gronau, W., \& Kagermeier, A. (2007). Key factors for successful leisure and tourism public transport provision. Journal of Transport Geography, 15(2), 127-135. https://doi.org/10.1016/j.jtrangeo.2006.12.008

Gündoğdu, F. K., Duleba, S., Moslem, S., \& Aydın, S. (2020). Evaluating public transport service quality using picture fuzzy analytic hierarchy process and linear assignment model. Applied Soft Computing, 100, 106920. https://doi.org/10.1016/j.asoc.2020.106920

He, D., Xu, J., \& Chen, X. (2016). Information-theoretic-entropy based weight aggregation method in multipleattribute group decision-making. Entropy. https://doi.org/10.3390/e18060171

Ilbahar, E., Karaşan, A., Cebi, S., \& Kahraman, C. (2018). A novel approach to risk assessment for occupational health and safety using Pythagorean fuzzy AHP \& fuzzy inference system. Safety Science, 103(2017), 124-136. https://doi.org/10.1016/j.ssci.2017.10.025

Jiang, W., Wei, B., Liu, X., Li, X., \& Zheng, H. (2018). Intuitionistic fuzzy power aggregation operator based on entropy and its application in decision making. International Journal of Intelligent Systems. https:// doi.org/10.1002/int.21939

Kaur, P. (2014). Selection of vendor based on intuitionistic fuzzy analytical hierarchy process. Advances in Operations Research, 2014, 1-10. https://doi.org/10.1155/2014/987690

Keeney, R. L. (2009). The foundations of collaborative group decisions. International Journal of Collaborative Engineering, 1(1/2), 4. https://doi.org/10.1504/IJCE.2009.027438

Khaleie, S., \& Fasanghari, M. (2012). An intuitionistic fuzzy group decision making method using entropy and association coefficient. Soft Computing. https://doi.org/10.1007/s00500-012-0806-8 
Khan, A. A., Shameem, M., Nadeem, M., \& Akbar, M. A. (2021). Agile trends in Chinese global software development industry: Fuzzy AHP based conceptual mapping. Applied Soft Computing. https://doi.org/ 10.1016/j.asoc.2021.107090

Lakatos, A., \& Mándoki, P. (2020). Mode-choice analysis in long-distance, parallel public transport. Transportation Research Procedia, 44, 332-341. https://doi.org/10.1016/j.trpro.2020.02.034

Lee, D.-J. (2018). A multi-criteria approach for prioritizing advanced public transport modes (APTM) considering urban types in Korea. Transportation Research Part a: Policy and Practice, 111, 148-161. https:// doi.org/10.1016/j.tra.2018.02.005

Li, X., Liao, H., \& Wen, Z. (2021). A consensus model to manage the non-cooperative behaviors of individuals in uncertain group decision making problems during the COVID-19 outbreak. Applied Soft Computing . https://doi.org/10.1016/j.asoc.2020.106879

Liao, H., \& Xu, Z. (2015). Consistency of the fused intuitionistic fuzzy preference relation in group intuitionistic fuzzy analytic hierarchy process. Applied Soft Computing, 35, 812-826. https://doi.org/10.1016/j.asoc. 2015.04.015

Liu, P., Zhang, X., \& Pedrycz, W. (2021). A consensus model for hesitant fuzzy linguistic group decisionmaking in the framework of Dempster-Shafer evidence theory. Knowledge-Based Systems. https://doi. org/10.1016/j.knosys.2020.106559

Liu, P., Zhu, B., \& Wang, P. (2021). A weighting model based on best-worst method and its application for environmental performance evaluation. Applied Soft Computing, 103, 107168. https://doi.org/10.1016/j. asoc. 2021.107168

Liu, Y., Eckert, C. M., \& Earl, C. (2020). A review of fuzzy AHP methods for decision-making with subjective judgements. Expert Systems with Applications. https://doi.org/10.1016/j.eswa.2020.113738

Macharis, C., \& Bernardini, A. (2015). Reviewing the use of multi-criteria decision analysis for the evaluation of transport projects: time for a multi-actor approach. Transport Policy, 37, 177-186. https://doi.org/10. 1016/j.tranpol.2014.11.002

Moslem, S., Alkharabsheh, A., Ismael, K., \& Duleba, S. (2020). An integrated decision support model for evaluating public transport quality. Applied Sciences, 10(12), 4158. https://doi.org/10.3390/app10124158

Narayanamoorthy, S., Geetha, S., Rakkiyappan, R., \& Joo, Y. H. (2019). Interval-valued intuitionistic hesitant fuzzy entropy based VIKOR method for industrial robots selection. Expert Systems with Applications, 121, 28-37. https://doi.org/10.1016/j.eswa.2018.12.015

Nutt, P. C. (2006). Comparing Public and Private Sector Decision-Making Practices. Journal of Public Administration Research and Theory, 16(2), 289-318. https://doi.org/10.1093/jopart/mui041

Otay, İ, Oztaysi, B., Cevik Onar, S., \& Kahraman, C. (2017). Multi-expert performance evaluation of healthcare institutions using an integrated intuitionistic fuzzy AHP\&DEA methodology. Knowledge-Based Systems, 133, 90-106. https://doi.org/10.1016/j.knosys.2017.06.028

Stanley, J., \& Stanley, J. (2020). Workshop 7 report: Assessing the wider benefits of public transport projects. Research in Transportation Economics, 83, 100914. https://doi.org/10.1016/j.retrec.2020.100914

Wang, Y. M., Luo, Y., \& Hua, Z. (2008). On the extent analysis method for fuzzy AHP and its applications. European Journal of Operational Research. https://doi.org/10.1016/j.ejor.2007.01.050

Wu, J., Huang, H., \& Cao, Q. (2013). Research on AHP with interval-valued intuitionistic fuzzy sets and its application in multi-criteria decision making problems. Applied Mathematical Modelling, 37(24), 9898-9906. https://doi.org/10.1016/j.apm.2013.05.035

Wu, Y., Liu, F., Huang, Y., Xu, C., Zhang, B., Ke, Y., \& Jia, W. (2020). A two-stage decision framework for inland nuclear power plant site selection based on GIS and type-2 fuzzy PROMETHEE II: Case study in China. Energy Science and Engineering. https://doi.org/10.1002/ese3.640

Xia, M., \& Xu, Z. (2012). Entropy/cross entropy-based group decision making under intuitionistic fuzzy environment. Information Fusion, 13(1), 31-47. https://doi.org/10.1016/j.inffus.2010.12.001

Xu, P., Wang, W., \& Wei, C. (2018). Economic and Environmental Effects of Public Transport Subsidy Policies: A Spatial CGE Model of Beijing. Mathematical Problems in Engineering, 2018, 1-12. https://doi.org/ $10.1155 / 2018 / 3843281$

Xu, Y., \& Wang, H. (2012). The induced generalized aggregation operators for intuitionistic fuzzy sets and their application in group decision making. Applied Soft Computing Journal. https://doi.org/10.1016/j. asoc.2011.11.003

Xu, Z. (2007). Intuitionistic fuzzy aggregation operators. IEEE Transactions on Fuzzy Systems. https://doi. org/10.1109/TFUZZ.2006.890678

Xu, Z., \& Liao, H. (2014). Intuitionistic Fuzzy Analytic Hierarchy Process. IEEE Transactions on Fuzzy Systems, 22(4), 749-761. https://doi.org/10.1109/TFUZZ.2013.2272585

$\mathrm{Xu}, \mathrm{Z}$., \& Yager, R. R. (2006). Some geometric aggregation operators based on intuitionistic fuzzy sets. International Journal of General Systems. https://doi.org/10.1080/03081070600574353 
Yao, D., \& Wang, C. (2018). Hesitant intuitionistic fuzzy entropy/cross-entropy and their applications. Soft Computing, 22(9), 2809-2824. https://doi.org/10.1007/s00500-017-2753-X

Yuan, J., \& Luo, X. (2019). Approach for multi-attribute decision making based on novel intuitionistic fuzzy entropy and evidential reasoning. Computers \&amp; Industrial Engineering, 135(June), 643-654. https:// doi.org/10.1016/j.cie.2019.06.031

Zhang, Z., Gao, Y., \& Li, Z. (2020). Consensus reaching for social network group decision making by considering leadership and bounded confidence. Knowledge-Based Systems. https://doi.org/10.1016/j.knosys. 2020.106240

Zhao, H., Xu, Z., Ni, M., \& Liu, S. (2010). Generalized aggregation operators for intuitionistic fuzzy sets. International Journal of Intelligent Systems. https://doi.org/10.1002/int.20386

Zyoud, S. H., Kaufmann, L. G., Shaheen, H., Samhan, S., \& Fuchs-Hanusch, D. (2016). A framework for water loss management in developing countries under fuzzy environment: Integration of Fuzzy AHP with Fuzzy TOPSIS. Expert Systems with Applications, 61, 86-105. https://doi.org/10.1016/j.eswa.2016.05.016

Publisher's Note Springer Nature remains neutral with regard to jurisdictional claims in published maps and institutional affiliations. 